\title{
NUMERICAL INVESTIGATION OF BONE TUMOR HYPERTHERMIA TREATMENT USING MAGNETIC SCAFFOLDS
}

A. Fanti, Member, IEEE, M. B. Lodi, G. Vacca and G. Mazzarella, Senior Member, IEEE

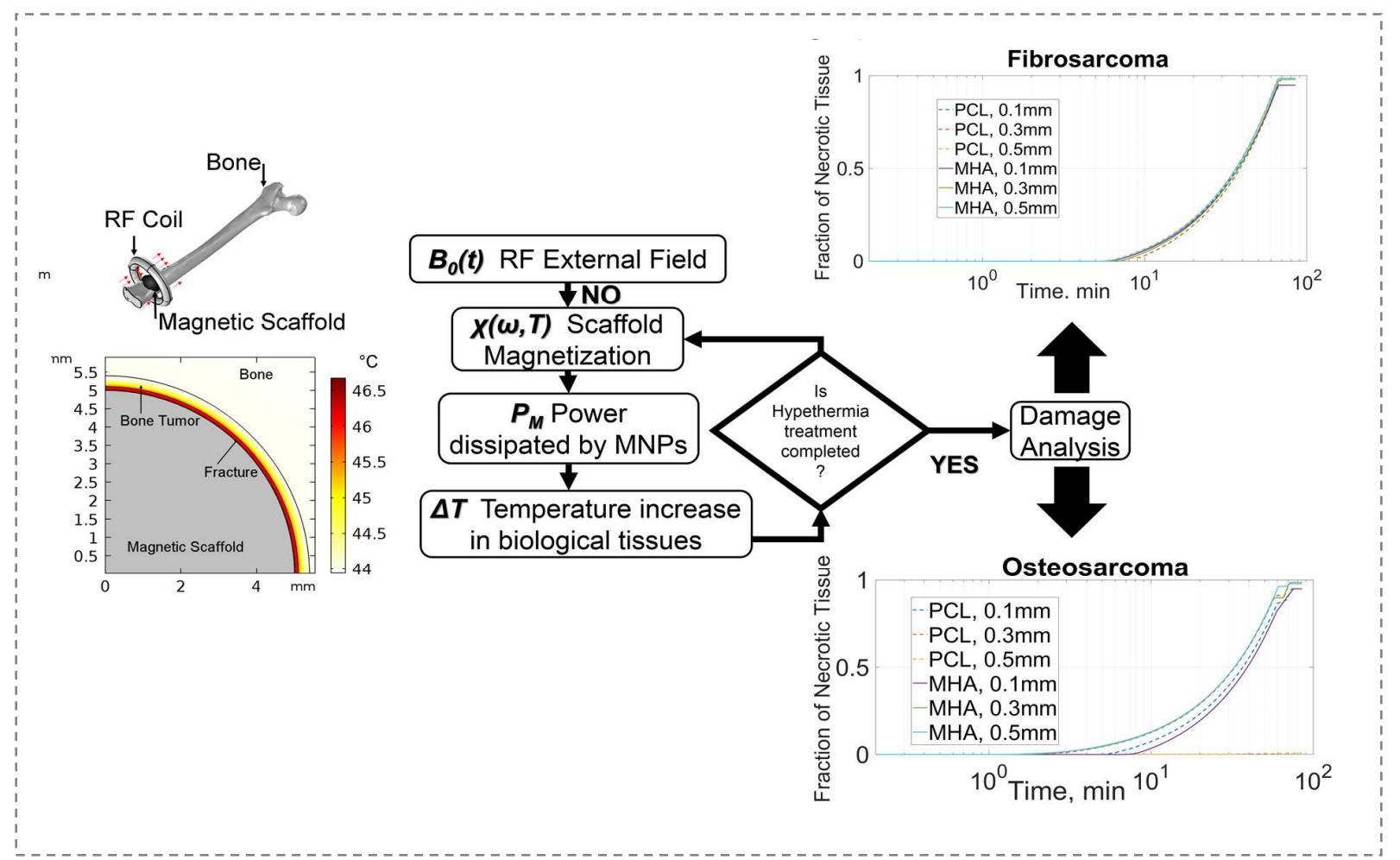

Modelling and in silico experiments of magnetic scaffolds for in situ hyperthermia treatment against Fibrosarcoma and Osteosarcoma tumors.

\section{Take-Home Messages}

- Functionalization of bone scaffolds using magnetic nanoparticles allows hyperthermia of bone tumors in an effective way.

- The possibility of employing innovative magnetic scaffolds as therapeutic tool in orthopaedic oncology is analyzed via numerical simulations. Using a Cole-Cole model, non-linear material properties are evaluated to define external field parameter to perform an effective treatment for bone tumors such as Fibrosarcoma and Osteosarcomas.

- Accurate electromagnetic and thermal modeling of scaffolds and nanoparticles, in the whole range of involved temperature, is required to design effective and safe treatments.

- Different tumoral tissues and qualitative features such as the presence, size and type of surgical fracture, affect in a significant way the hyperthermia treatment. 


\title{
NUMERICAL INVESTIGATION OF BONE TUMOR HYPERTHERMIA TREATMENT USING MAGNETIC SCAFFOLDS
}

\author{
A. Fanti, Member, IEEE, M. B. Lodi, G. Vacca and G. Mazzarella, Senior Member, IEEE
}

\begin{abstract}
This works claims to define, via numerical simulations, magnetic field parameters to perform an effective in situ bone tumor hyperthermia treatment using magnetic scaffolds. A Cole-Cole model to describe the frequency response of the magnetic susceptibility of nanoparticles embedded in novel magnetic biomaterials is explored. The heating phenomena is investigated considering both the ischemic and inflamed state of the fracture gap at the bone/implants interface. Both Osteosarcoma and Fibrosarcoma tumors are analyzed. Magnetic hydroxyapatite and poly- $\varepsilon$-caprolactone scaffolds are investigated. From the thermal analysis, it is found that the fracture behaves as a resistance to heat conduction, therefore strength and frequency of external magnetic field has to be tuned to perform the treatment taking the fracture status into account. Moreover, numerical experiments indicate that low perfused Fibrosarcoma can be treated using moderate-strength field, whereas more intense external fields are required to treat strongly vascularized Osteosarcoma without damaging healthy bone tissue. Magnetic hydroxyapatite stands out to be the most performant and versatile material to treat both tumors. These simulations can be regarded as a starting point to analyze possible clinical use of magnetic scaffolds for in situ bone hyperthermia.
\end{abstract}

Keywords - Biomagnetics, Electromagnetic fields, Heat treatment, Hyperthermia, Magnetic particles, Tumors.

\section{INTRODUCTION}

B ONE cancers are a wide class of relatively rare neoplasms, mostly afflicting patients between the ages of 10 and 20 years [1], with an incidence of about 3 cases out of $100^{\prime} 000$ persons per year [1]-[3]. Bone neoplasms can be classified in benign, intermediate or malignant. Moreover, since tumors can originate from tissues different from bone, it is necessary to distinguish between boneforming cancers (Osteosarcomas, i.e. OS), cartilageforming (Chondrosarcomas), bone-marrow (Ewing sarcoma), and soft-tissue ones (Fibrosarcoma, i.e. FS) [2]. OS are aggressive malignant bone tumors whose cells produce bone matrix or osteoid [1]-[3]. Furthermore, OS can reach $5 \mathrm{~cm}$ and grow in an angiocentric fashion, implying a noticeable vascularization [1]-[3]. Prognostic factors depend on treatments, though survival rate ranges from $30 \%$ to $40 \%$ [1]. On the other hand, FS is a malignant neoplasm arranged in a fascicular architecture of interlaced trabecular bundles. It tends to extend to soft tissues [1]. A 10 -year survival rate equal to $28 \%$ for this kind of neoplasm has been reported in [4]. Both OS and FS mostly affect long bones, namely distal femur, proximal or upper part tibia,

Alessandro Fanti, Matteo Bruno Lodi, Giuliano Vacca, Giuseppe Mazzarella are with Department of Electrical and Electronic Engineering, University of Cagliari, P.zza d'Armi, 09123 Cagliari, Italy, (email: alessandro.fanti@diee.unica.it, matteobrunolodi94@gmail.com, giuliano.vacca@outlook.it, mazzarella@diee.unica.it ). and humerus [1], [2], [4]. Therefore, the distinct clinical features, together with the pathological and histological characteristics of the cited lesions, determine different staging and treatment. Currently, the main treatment strategies are chemotherapy, radiotherapy, osteotomies, ablative surgery or intralesional excision (i.e. curettage) [1], [3]. However, approximately $15 \%$ of surgical intervention results in tumor recurrence [3]. To overcome this clinical issue, several novel techniques aimed to kill residual cancer cells have been proposed, e.g. combined radiotherapy and chemotherapy protocols, hyperthermia, immunotherapy and smart drug nanocarriers [5]-[9].

Hyperthermia (HT) stands out to be a very promising approach [5], [9], [10]. Its thermo-biological rationale is to selectively rise tumor temperature above $42.5{ }^{\circ} \mathrm{C}$ for a time sufficient to impair transmembranal transport, inducing cytotoxicity determining cancer cells death and eliciting immune system response [9], [10]. Moreover, temperature rise increases cells permeability to antitumor drugs, allowing a synergic effect with chemotherapy [9], [10]. Hyperthermia can be induced by ultrasounds or Electromagnetic (EM) fields exposure [9]. Fan et al. developed a surgical method that exploited EM hyperthermia [11]. In their study, 62 patients with various bone tumors (among them 30 OS, 4 FS) have been treated, in situ, with an antenna array while monitoring tumor temperature to keep it above $65{ }^{\circ} \mathrm{C}$. An $8 \%$ recurrence rate, infections and six deaths were reported. In [11] it is stressed the clinical need for a proper management of the 
pathological fractures after surgery, such as grafts or the use of bone scaffolds to withstand tissue regeneration. This need has led to the development of novel magnetic biomaterials to be used both as scaffolds for tissue support after curettage, and as heat source for local magnetic induction HT treatment of bone tumor [12]-[14]. Following surgery, after magnetic scaffold placement, therapeutic heat is generated and conducted to surrounding tissues by remotely applying an alternate magnetic field (MF) through an external coil [13]-[15]. In this way, temperature can increase above $43^{\circ} \mathrm{C}$, thus killing residual cancer cells and allowing healthy tissue to grow sustained by the implant [13], [14]. A very first attempt was the ferromagnetic bioglass intermedullary pin proposed by Ikenaga et al. [15]. The device was tested in vivo against VX2 tumor cells. A temperature raise of $13^{\circ} \mathrm{C}$ was obtained after $50 \mathrm{~min}$, leading to a decrease in fracture rate [15]. After that, different kinds of ferro- [15], [16] and ferrimagnetic glass [16], [17] ceramics have been synthetized and characterized to ensure the use of these biomaterials for HT purposes [16]-[19].

Further interesting and innovative scaffolds biomaterials, able to perform in situ HT of bone tumor, are based on superparamagnetic iron oxide nanoparticles (SPIONs) [20]. Blocking temperature, susceptibility and power losses of SPIONs, which are determinant for hyperthermia applications [13], [20] can be easily tailored; [21]. Superparamagnetic scaffolds can be easily produced by embedding magnetic nanoparticles (MNPs) in porous traditional bone tissue engineering materials (e.g. ceramics, natural and synthetic polymers), as reported in [22]. Moreover, through a chemical doping of hydroxyapatite (Ha) with $\mathrm{Fe}$ ions, intrinsically magnetic and bioactive $\mathrm{Fe} / \mathrm{Ha}$ nanoparticles and scaffolds (henceforth MHA) were synthetized [23]. As a matter of fact, different MNP can show completely different responses. For example, MHA demonstrated a temperature increase of $40{ }^{\circ} \mathrm{C}$ in $1 \mathrm{~min}$, whereas the polycaprolactone (PCL) scaffold loaded with magnetite $\left(\mathrm{Fe}_{3} \mathrm{O}_{4}\right)$ reached a $9{ }^{\circ} \mathrm{C}$ increase in $5 \mathrm{~min}$, both using an external MF of $30 \mathrm{mT}$ at $293 \mathrm{kHz}$ [22], moreover using different exposure conditions.

All the studies on magnetic scaffolds focus on the synthesis, characterization and proof-of-concept of such therapeutic biomaterials [24-29]. However, none of them has ever modeled completely the physical properties of the scaffolds to accurately define hyperthermia treatment, also including and simulating healthy and pathologic tissues. To start bridging the gap, this work deals with the numerical simulation of in vivo magnetic induction hyperthermia of Osteosarcoma and Fibrosarcoma tumor cells [1]-[5] in presence of the $\mathrm{FeHa} / \mathrm{PCl}$ and $\mathrm{MHA}$ superparamagnetic scaffolds described in [13], [22], [23] when exposed to a time-varying MF. Aim of this work is to model scaffold and MNPs properties and to connect them with HT treatments of bone tumors. The final goal is to help choosing strength, frequency and waveform of external MF required to perform an optimal treatment. In section II, SPIONs properties. In section III the bio-heat transfer model is presented, explained and discussed. In section IV details on geometry and parameters used in the simulations are TABLE I

PROPERTIES OF MAGNETIC SCAFFOLDS FOR BONE TUMOR HYPERTHERMIA

\begin{tabular}{|c|c|c|}
\hline Magnetic Scaffold & 恿畺 & 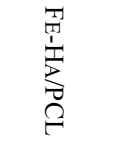 \\
\hline Magnetite Crystal radius (nm) & 10 & 14 \\
\hline Magnetic Phase (vol \%) & 1.6 & 9.18 \\
\hline Saturation Magnetization $\left(\mathrm{emu} \mathrm{g}^{-1}\right)$ & 0.95 & 6 \\
\hline Maximum Heating $\left({ }^{\circ} \mathrm{C}\right)$ & 40 & 10 \\
\hline Time (min) & 1 & 5 \\
\hline Magnetic Flux Density Field Strength (mT) & 30 & 30 \\
\hline Working Frequency $(\mathrm{kHz})$ & 293 & 293 \\
\hline Reference & {$[22],[23]$} & {$[22],[23]$} \\
\hline
\end{tabular}

summarized. The non-linear behavior of the heating phenomenon is taken into due account. The influence of physiological and pathological factors such as tumor stage and bone healing process are included in the presented analysis. In section V, optimized magnetic field parameter, temperature spatial distribution and temporal development in tumor region for the different materials analyzed therein are reported. Finally, in section VI some conclusions are drawn.

\section{POWER DISSIPATION OF MAGNETIC BIOMATERIALS IN TISSUES}

\section{A. EM Model}

SPIONs can be magnetized by an external magnetic field, and the strength of this magnetization is proportional to the (complex) magnetic susceptibility $\chi=\chi^{\prime}-j \chi^{\prime \prime}$. For an alternating field at a frequency $\mathrm{f}$, the magnetic volumetric power dissipation density is [30]:

$$
P_{M}=\mu_{0} \pi f H^{2} \chi^{\prime \prime}
$$

where $\mu_{0}=4 \pi \cdot 10^{-7} \mathrm{Hm}^{-1}$ is the vacuum permeability. $\mathrm{H}$ in (1) is the magnetic field at the SPION location, which must be computed, given the external magnetic flux density. Maxwell's equations are therefore solved in the frequency domain to determine actual magnetic field, $\mathrm{H}$, acting on the SPIONs. Moreover, since dielectric losses may contribute to heating phenomena [31], the electric field E, due to the Faraday Law, is determined to compute the associated dissipated power $\left(\mathrm{P}_{\mathrm{E}}\right)$ and hence quantify the overall electromagnetic losses $\left(\mathrm{Q}_{\mathrm{EM}}\right)$ to determine the temperature increase. The MNPs, with radius and saturation magnetizations given in Tab. I, are assumed to be uniformly dispersed in either a hydroxyapatite or a PCL scaffold described in [22], with radius $r_{s}=0.5 \mathrm{~mm}$ (Fig. 2). The commercial Finite Element Method (FEM) software COMSOL Multyphisics (COMSOL inc., Burlington, MA), 
TABLE II

DIELECTRIC PROPERTIES OF SCAFFOLDS MATERIALS AND TISSUES

\begin{tabular}{|c|c|c|c|c|c|}
\hline & $\varepsilon(293 \mathrm{kHz})$ & $\sigma(293 \mathrm{kHz}), \mathrm{Sm}^{-1}$ & $\varepsilon(409 \mathrm{kHz})$ & $\sigma(409 \mathrm{kHz}), \mathrm{Sm}^{-1}$ & References \\
\hline $\mathrm{Ha}$ & $12.5-\mathrm{j} \cdot 0.5$ & $2.1 \cdot 10^{-3}$ & $11.98-\mathrm{j} \cdot 0.47$ & $2.5 \cdot 10^{-3}$ & [54] \\
\hline PCL & $2.2-\mathrm{j} \cdot 0.125$ & $10^{-5}$ & $2.15-\mathrm{j} \cdot 0.120$ & $0.3 \cdot 10^{-4}$ & {$[57]$} \\
\hline Fracture (inflamed) & $3580-\mathrm{j} \cdot 33451$ & 0.545 & $3360-\mathrm{j} \cdot 24491$ & 0.557 & derived from [58] \\
\hline Fracture (ischemic) & $1321.5-\mathrm{j} \cdot 12030$ & 0.196 & $1241.5-\mathrm{j} \cdot 8494$ & 0.2 & derived from [58] \\
\hline Bone & $192-\mathrm{j} \cdot 1313.5$ & 0.0214 & $182-\mathrm{j} \cdot 959$ & $2.18 \mathrm{e}-2$ & {$[60]$} \\
\hline Bone tumors (FS and OS) & $8000-\mathrm{j} \cdot 17186$ & 0.280 & $3600-\mathrm{j} \cdot 11432$ & 0.26 & [59] \\
\hline
\end{tabular}

Magnetic Fields module is used to solve Maxwell equations and simulate superparamagnetic scaffold response.

In a low viscosity regime, the frequency response of a dispersion of MNPs has been described in terms of a Debye model and the Rosensweig theory justifies the behavior of ferrofluids [30]. Whereas, in a significant viscosity regime, as suggested by Tampieri et al. [23] and measured by Hergt et al. [31], the sticky medium inhibits dissipation mechanisms, thus strongly influences the power loss of a MNPs ensemble. In a highly viscous or solid matrix the resonance vanishes, since Brownian relaxation cannot occur [31], [32]. Hence, only Néel mechanism should be considered to explain heating efficiency of scaffolds magnetic phase [31], [37]. In this configuration the interparticle strong dipolar interactions limit the MNPs relaxation dynamic [33]. Therefore, since the Debye response vanishes and long-range interactions between particles become important [31]-[34], magnetic scaffolds experimental heating curves from Bañobre-López et al. [20] and Tampieri et al. [23] should be described using a ColeCole model for magnetic susceptibility, $\chi(\omega)$, as [34], [35]:

$$
\chi(\omega)=\chi^{\prime}-j \chi^{\prime \prime}=\frac{\chi_{0}}{1+(j \omega \tau)^{1-\gamma}}
$$

where $\omega$ is the angular frequency. and $\gamma$ is the so-called Cole-Cole exponent, which describes the broadness of the relaxation time distribution. Fitting the data from [31], $\gamma$ was previously found to be 0.750 [34]. Therefore, power losses evaluated with Cole-Cole correction can justify magnetic scaffolds heating curves reported by BañobreLópez et al. [22] and Tampieri et al. [23]. The characteristic Néel relaxation time $\tau$ in Eq. (2) can be computed as [30]:

$$
\tau=\frac{\sqrt{\pi}}{2} \beta \tau_{0} \frac{e^{\beta}}{\sqrt{\beta^{3}}}
$$

where $\beta=K_{a} V_{m} / k_{B} T$, being $\mathrm{K}_{\mathrm{a}}$ the magnetic anisotropy energy in $\mathrm{Jm}^{-3}, \mathrm{~V}_{\mathrm{m}}$ the magnetic nanoparticle volume in $\mathrm{m}^{3}$, $\mathrm{k}_{\mathrm{B}}$ the Boltzmann constant in $\mathrm{JK}^{-1}$ and $\mathrm{T}$ the system temperature in $\mathrm{K}$. The constant $\tau_{0}$ can be evaluated according to [36] as:

$$
\tau_{0}=\frac{\pi}{4} \frac{\left(M_{s}(0) V_{m}\right)}{K_{a} \gamma_{e}}\left[\frac{1}{\eta_{f}}+\eta_{f}\left(\frac{M_{s}(T)}{M_{s}(0)}\right)^{2}\right] \sqrt{\frac{k_{B} T}{K_{a}}}\left(1+\frac{k_{B} T}{K_{a}}\right)
$$

where $\gamma_{\mathrm{e}}$ is the electron gyromagnetic ratio in $\operatorname{rad~s}^{-1} \mathrm{~T}^{-1}$ and $\eta_{f}=\eta \gamma_{e} M_{s}(0)$, being $\eta$ the damping factor, equal to 0.25
[36]. The values of $M_{s}(T)$ were derived from the curves reported in [23]. Finally, $\chi_{0}$ is the equilibrium susceptibility and it is calculated as suggested by [37]:

$$
\chi_{0}=\frac{\mu_{0} \varphi V_{m} M_{s}^{2}}{3 k_{B} T}
$$

where $\varphi$ is the volume ratio of the magnetic phase in the scaffold. The power dissipated by magnetic scaffolds is a function of the frequency and intensity of the applied magnetic field, which can be tuned, tailored and remotely controlled [31], [34], [35], [38]. Moreover, power losses are strictly related to magnetic phase in bone scaffold, to particle radius and blocking temperature of the sample [19], [23], [35]. On the other hand, dissipation depends also on the magnetic susceptibility of the sample (scaffold [32], [34]). This susceptibility has a strong temperature dependence, as shown in Eq. (3) to (5), and therefore the heating process is a non-linear one. Therefore, the Maxwell and the heat equation must be solved using a coupled multiphysics approach [39]. The magnetic field frequency of interest is quite low, and therefore a coupled resolution scheme is directly implemented in COMSOL Multiphysics using Magnetic Fields and Heat Transfer Modules.

\section{B. Numerical evaluation of magnetic material properties}

As explicitly shown by eq. (5), the larger the saturation magnetization or the magnetic phase in scaffold volume, the stronger the initial or equilibrium susceptibility $\chi_{0}$. The imaginary part of $\chi(\omega)$ depends in turn from $\chi_{0}$ and hence do power losses in magnetic implants. This argument agrees with experimental data for both MHA and FeHa/PCL [22] (see Tab. III). However, $\chi_{0}$ inversely depends on temperature, since the energy barrier increases with $\mathrm{T}$ and the material become less magnetizable [36]-[38], [40]. In Fig. 1 the susceptibility dependence on temperature is shown for MHA. On the other hand, the characteristic Néel relaxation time strongly influences the power dissipated in magnetic scaffolds through Eqs. (3) and (4). Exploiting magnetization curve vs. temperature from [23], $\tau_{0}$ and $\tau_{\mathrm{N}}$ are depicted in Fig. 1. These results agree qualitatively with [41]. Merging these findings, it is possible to infer that $P_{M}$ decreases with temperature since $\chi$ " slightly diminishes, as shown in Fig. 1. Heating would therefore tend to saturate.

To assess the use of Eq. (2), the Debye model (imposing $\gamma=0$ in Eq. (2)) and the Cole-Cole model were employed in the case of bone alone, to compute the power dissipated and the final temperature increase in response to a constant magnetic flux density field (30 mT, $293 \mathrm{kHz}$ [22], $60 \mathrm{~min})$. Both $\mathrm{P}_{\mathrm{M}}$ and temperature calculated with Debye are two 
orders of magnitude lower than Cole-Cole ones and do not agree with experimental findings of [22]. Therefore, as hunched from [31] and suggested by [33], [34], the ColeCole model can be assumed as an effective model for the behavior of the materials in Tab. III.

\section{BIO-HEAT TRANSFER MODEL}

The temperature increase of tissues under the effect of an "exogenous" power source $Q_{E M}$ can be determined by the Pennes bio-heat equation [42], [43]:

$$
\rho C_{p} \frac{\partial T}{\partial t}=k \nabla^{2} T+\left[\rho_{b} C_{p, b} \omega_{b}\left(T_{a}-T\right)\right]+Q_{M}+Q_{E M}(6)
$$

where $\rho$ is the density in $\mathrm{g} \mathrm{m}^{-3}, C_{p}$ is the specific heat capacity in $\mathrm{Jkg}^{-1} \mathrm{~K}^{-1}, k$ is the thermal conductivity in $\mathrm{Wm}^{-}$ ${ }^{2} \mathrm{~K}^{-1}$. The term in brackets represents the capillary perfusion, i.e. blood thermal contribution which acts to equilibrate surrounding tissues with arterial temperature $\mathrm{T}_{\mathrm{a}}=37^{\circ} \mathrm{C}(310.15 \mathrm{~K})$. The perfusion of normal and tumoral tissue was included in the model by a piecewise

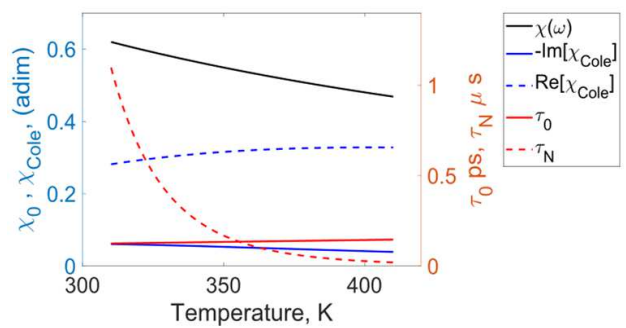

Fig. 1. Equilibrium magnetic susceptibility $(\chi 0)$, real and imaginary part of susceptibility according to Cole-Cole model [38] as a function of temperature (adim). The external magnetic flux density field is set to $1 \mathrm{mT}$ and $293 \mathrm{kHz}$. Temperature influence on constant $\tau 0$ according to [32] and on Néel relaxation time is drafted. Magnetic power losses as a function of temperature can be quantified with the presented model.

approximation to reproduce the temperature-dependence of chart. 7 at page 4726s of [44] and Fig. 6 at page 512 of [45] .The form of Eq. (6) ensures a $1.38 \%$ relative error with respect to in vivo studies [42], [43], [46]. There are two source terms in (6). One is the metabolic heat $\mathrm{Q}_{\mathrm{M}}$, while the term $Q_{E M}$ is, in our case, the power dissipated due to dielectric and magnetic losses, and it is computed from electric and magnetic field assuming scaffolds and tissues as volumetric heat sources. Eq. (6) is subject to zero flux boundary condition at bone boundary, i.e. $-\hat{n} \cdot(k \nabla T)=0$

. The initial temperature $\mathrm{T}_{0}$ is assumed equal to $310.15 \mathrm{~K}$ for all tissues, except for the inflamed fracture $(308.15 \mathrm{~K}$ ) [47]. The fraction of damaged necrotic tissue has been evaluated considering the definition given by Sapareto and Dewey [48], [49], normalized to the damage time $t_{D}$. Both OS and FS tumors, and the fracture are considered damaged if temperature is kept above $43{ }^{\circ} \mathrm{C}(316.15 \mathrm{~K})$ for $60 \mathrm{~min}$ [9]-[12], [17], [22], [25]. Of course, also healthy bone tissue is heated, but by conduction from the tumor. Therefore, it is necessary to design the hyperthermia treatment in an effective way while preventing the necrosis of healthy bone tissue, which occurs if temperature increases up to $47{ }^{\circ} \mathrm{C}$
(320.15 K) for more than $1 \mathrm{~min}$, as reported in [25], [50], [51].

\section{Simulation}

\section{A. Geometry}

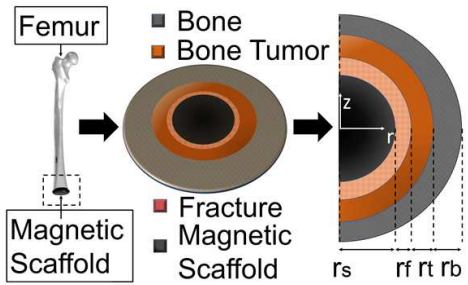

Fig. 2. The case of a scaffold implanted after long bone tumor surgical treatment is analyzed. A transverse section of bone, residual cancer tissue, fracture gap and scaffolds are considered, with radius $r_{b}, r_{t}, r_{l}, r_{s}$ respectively. Given a spherical scaffold, system geometry is $2 \mathrm{D}$ axialsymmetric with $\mathrm{r}$ - and $\mathrm{z}$-axes origin set in scaffold center

OS and FS affect mainly long bones extremities [1]-[4]. Therefore, in this paper, the case of a magnetic scaffold implanted in distal femur after surgical intervention is analyzed, as depicted in Fig. 2. Since the aim of this work is to evaluate the main determinants for in situ hyperthermia treatment of bone neoplasms through magnetic scaffolds, the problem is simplified considering a circular 2D axialsymmetric geometry (Fig. 2).

Therefore, a very narrow volume of tissue around the implant is considered [15], [16], [20], [34], [52]. A homogenous uniform external magnetic flux density field $\mathrm{B}_{0}$ is assumed applied along the $\mathrm{z}$-axis. The origin of the system is assumed centered on the scaffold. The orthopaedic implant has a radius of $5 \mathrm{~mm}$ [13], [15], [34], [35], [52]. Near the scaffold, there is a region where new bone forms to heal surgical fracture [53]-[54]. Healing process starts with hematoma and local ischemia (first 7 days), and ends with an inflammatory phase (up to 14 days), which leads to callus formation [53]. For this reason, a small fracture with radius varying in the range $0.1 \div 0.5$ $\mathrm{mm}$ [54] has been considered, as in Fig. 2. The tumor region is modeled as a uniform tissue spherical area of radius $r_{t}$. The bone tumor volume is assumed to be reduced after surgical intervention [1]-[4], [11], [12]. The tumor radius has been varied from $0.1 \mathrm{~mm}$ to $0.5 \mathrm{~mm}$.

\section{B. Simulation Parameters}

The relative magnetic permeability of the fracture, the tumor and the bone is assumed equal to one. As stated in Section II.A, also the dielectric losses are needed to compute the proper temperature distribution under the external MF. In order to model frequency response of both dielectric permittivity and conductivity of hydroxyapatite, data and relations from [55]-[56] were employed. For PCL it is possible to refer to [57]-[58] for its dielectric properties. The dielectric permittivity of the fracture gap was estimated employing the mixing model used in [59]. In fact, it is possible to discriminate between the ischemic and inflamed phase by weighing bone permittivity with blood 
one. Whereas, tumor dielectric properties are derived from data of a 15 days tumor staging by the work of Swarup et al. [60]. Dielectric permittivity and electrical conductivity of all materials are reported in Tab. II for the frequencies of interest. Dielectric properties are assumed to vary linearly with temperature (with a variation of $3 \%{ }^{\circ} \mathrm{C}^{-1}$ ) as suggested by Rossman et al. [61].

Some considerations on thermal proprieties of the involved materials are also in order. The $C_{p}$ (except for blood) and all the $k$ have been assumed linear with temperature, with a $1{ }^{\circ} \mathrm{C}$ increase of $0.5 \%$ and $0.33 \%$ respectively [61], [62]. $\mathrm{C}_{\mathrm{p}}$ for blood has been assumed linear with a $1{ }^{\circ} \mathrm{C}$ reduction of $1 \%$ [61]. Bone properties are taken from the IT'IS database [63]. For the two stages, fracture properties are derived from [64]. Regarded histological section presented in [1]-[3], bone tumor cells can be assumed uniformly dispersed in bone matrix [62], hence the uniformity assumption is justified. The cases of OS and FS are both considered. Highly vascularized OS is represented with a perfusion rate about 250 times higher than fibrosarcoma, as derived from [45]. On the other hand, to the best of the authors' knowledge, no data about thermal parameters are available for any of the studied bone tumor. Tumor thermal conductivity and heat capacity has been therefore assumed [46] to be equal to those of bone [63], since from histological sections found in [2]-[5] both OS and FS cells are regarded as a uniform dispersion in bone matrix. The metabolic heat source term, $Q_{M}$, is set to 57240 $\mathrm{Wm}^{-3}$ to account for the higher metabolic activity of cancer cells [46]. All thermal properties employed in the simulations are reported in Table III at the initial temperature. Employing data from Tab. I-III, the temperature influence on magnetic power losses is first investigated. Then, in absence of tumor $\left(r_{t}=0 \mathrm{~mm}\right)$, heating for different radius of the fracture was assessed for both MHA and FeHa/PCL in presence of an uniform external magnetic field of $1 \mathrm{mT}$ and $293 \mathrm{kHz}$. Finally, considering a small fracture $\left(r_{f}=0.1 \mathrm{~mm}\right)$, Fibrosarcoma and Osteosarcoma tumors volume was varied, and magnetic field strength, frequency and waveform were tailored to obtain the maximum damage of cancer cells (see summary table in the supplementary material). This will be available at http://ieeexplore.ieee.org.

\section{RESULTS}

The working frequencies and the order of magnitude of the external magnetic field have been chosen equal to those of [22] and [25]. The evaluated spatial temperature patterns are qualitatively similar in each case analyzed, therefore only the $\Delta \mathrm{T}$ distribution for OS after $85 \mathrm{~min}$ is presented in Fig. 3. A time-lapse animation of the heating in the case of MHA and both FS and OS with $0.5 \mathrm{~mm}$ radius is however given in the supplementary material. This will be available at http://ieeexplore.ieee.org. Being the external field homogeneous, and since the scaffold is spherical, the resulting heating is uniform and homogeneous. Henceforth relevant attention is paid only to temporal variation of temperature in tissues [22], [50] and to damage analysis [48].

The first test has been performed for $r_{t}=0$ (i.e. without a tumor), for different gap width (for $\mathrm{r}_{\mathrm{f}}=0.1,0.3,0.5 \mathrm{~mm}$ ) and status (inflamed and ischemic stages). As the actual heating does not take place as direct conduction from magnetic implant to the bone, the presence of the surgical fracture gap has been included to assess its influence. In Fig. 4 is reported the average temperature in the gap during the heating, for $\mathrm{B}_{0}=1 \mathrm{mT} @ 293 \mathrm{kHz}$, in presence of the MHA scaffold. Using PCL scaffold produce analogous results and, hence, they are not reported herein. Fig. 3 shows clearly that the external field required by the HT treatment must be evaluated taking into account the fracture, and its state. Otherwise, the required external field will be largely underestimated. In case of an ischemic fracture, the strength of external field should be increased with respect to the inflamed state to achieve the same desired temperature increase. Therefore, in situ hyperthermia treatment with magnetic scaffolds should be performed immediately after surgery. FS is a poorly vascularized type of bone tumor; therefore, it holds that $P_{M} \gg \rho_{B} C_{p, B} \omega_{B}\left(T_{a}-T\right)$, as observed during numerical experimentation. Hence, moderate magnetic field strength allow to keep the temperature above $43^{\circ} \mathrm{C}$ for $60 \mathrm{~min}$ in tumor [10] (Fig. 5a). To prevent healthy bone to overcome the safety limit $\left(47^{\circ} \mathrm{C}\right.$ for $1 \mathrm{~min}$ or more [25]) the field envelope cannot be constant, and must be properly designed. The envelope of Fig. 5a has been optimized to get an effective treatment. For PCL, a $17 \mathrm{mT}$ field at $293 \mathrm{kHz}$ is sufficient to completely disrupt bone tumor of any dimension, as presented in Fig. 5b. On the other hand, MHA, which has stronger saturation magnetization (Tab. I), requires $10 \mathrm{mT}$. The OS is a very active and perfused tumor [1], therefore stronger fields are required to achieve the therapeutic performance. A constant magnetic flux density (see Fig. 5c) applied for $85 \mathrm{~min}$, can efficiently treat OS with MHA scaffolds. The required external field must, however, be increased for larger $r_{t}$. For MHA the magnetic field strengths ranges from $20 \mathrm{mT}$ up to $50 \mathrm{mT}$ at $293 \mathrm{kHz}$. For the $\mathrm{FeHa} / \mathrm{PCL}$ scaffold, the frequency was augmented to $409 \mathrm{kHz}$, as in [25]. Without

TABLE III

THERMAL PROPERTIES AT $37^{\circ} \mathrm{C}$ OF SCAFFOLDS MATERIAL AND TISSUES

\begin{tabular}{|c|c|c|c|c|c|}
\hline & $\mathrm{k}\left(\mathrm{Wm}^{-1} \mathrm{~K}^{-1}\right)$ & $\mathrm{C}_{\mathrm{p}}\left(\mathrm{J} \mathrm{kg}^{-1} \mathrm{~K}^{-1}\right)$ & $\mathrm{Q}_{\mathrm{M}}\left(\mathrm{Wm}^{-3}\right)$ & $\omega_{\mathrm{B}}\left(\mathrm{s}^{-1}\right)$ & References \\
\hline $\mathrm{Ha}$ & 1.3 & 700 & 1 & 1 & [34] \\
\hline PCL & 1.75 & 1300 & / & / & [34] \\
\hline Fracture (inflamed) & 0.558 & 2450 & 5262.5 & $6.95 \mathrm{e}-3$ & [46] \\
\hline Fracture (ischemic) & 0.1 & 2450 & 342.1 & $0.262 \mathrm{e}-3$ & [46] \\
\hline Bone & 0.32 & 1313 & $286.2 \div 57240$ & $0.175 \mathrm{e}-3$ & [60] \\
\hline FS & 0.32 & 1313 & $286.2 \div 57240$ & $2.4 \mathrm{e}-3$ & {$[60],[62]$} \\
\hline OS & 0.32 & 1313 & $286.2 \div 57240$ & 0.595 & {$[60],[62]$} \\
\hline
\end{tabular}


this frequency change, large OS could not be successfully treated, as shown in Figures $5 \mathrm{c}$ and $5 \mathrm{~d}$. It should also be noted that $\mathrm{FeHa} / \mathrm{PCL}$ fails in treating OS with radius higher than $0.1 \mathrm{~mm}$ even using a field at $409 \mathrm{kHz}$, unless the field intensity is significantly larger than $50 \mathrm{mT}$ [22], [25]. This finding implies that different MNPs, with a higher volume ratio, should be embedded in the scaffold, as well as; field strength and frequency ought to be increased to achieve the same performances of MHA. However, the product $f \cdot H$ has to be controlled, as dictated by Pankhurst et al. [33]. The biocompatibility of the implant is a major requirement for this application [20]. Despite these reasonable limitations, the presented simulation model can give a firstestimate of hyperthermia potential of any type of magnetic scaffold.

\section{CONCLUSION}

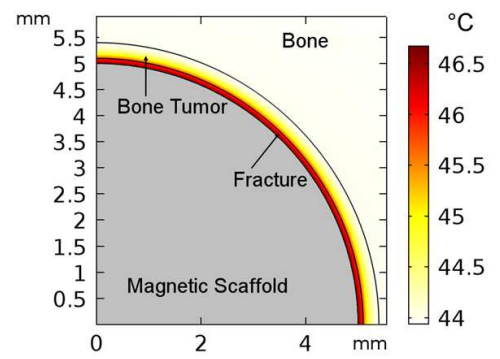

Fig. 3. Zoom of the 2D distribution of temperature in tissues. The case of a $0.3 \mathrm{~mm}$ OS is presented. A $28 \mathrm{mT}$ and $293 \mathrm{kHz}$ field is employed.

A coupled thermal-electromagnetic model for hyperthermia treatment of bone tumor using MNPs and magnetic scaffolds has been devised. This model takes into account

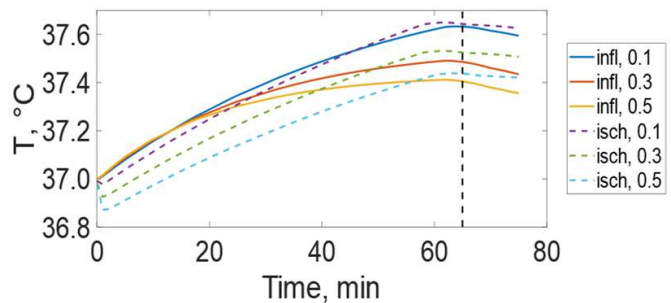

Fig. 4. Average temperature in fracture volume vs. time and for both the inflamed and ischemic case. The dashed black line indicates the time point at which the external RF magnetic field is turned off

in an integrated way several important non-linear properties of magnetic materials, but also physiological and physical features of the in vivo hyperthermia treatment of bone tumors, which were only partly considered before. Particular care has been given to take into account the strong temperature dependence of nanoparticles magnetic susceptibility, which leads to non-linear effects during the treatment. An important finding is the relevance of the status of the surgical fracture gap on the tumor heating, which supports the use of hypertermia several days after surgical intervention. As a result, the temperature in tumour tissues can be evaluated with more accuracy, allowing a more realistic design of the treatment. This has been found particularly important in FS treatment. As a matter of fact, the FS has a poor vascular structure, without an optimized design of an uniform external magnetic field, and therefore, can be easily overheated during the treatment, increasing the temperature of healthy bone tissues into the unsafe region. It is worth nothing that the presented model can be quite easily adapted to lively problems, such as the use of magnetic scaffolds in thermally-activated drug delivery.

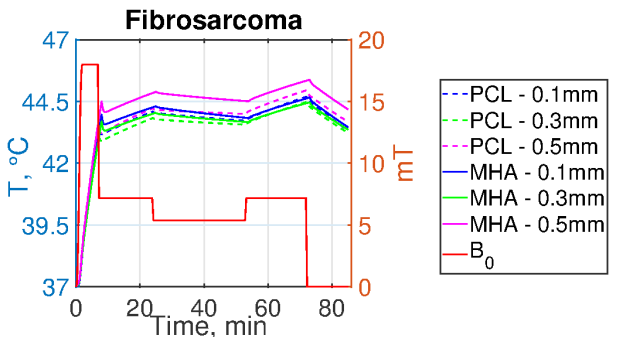

(a)

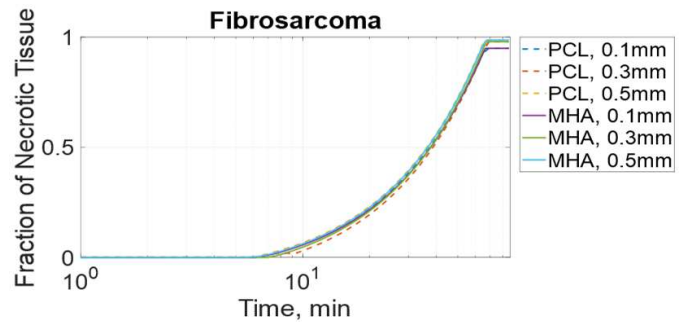

(b)

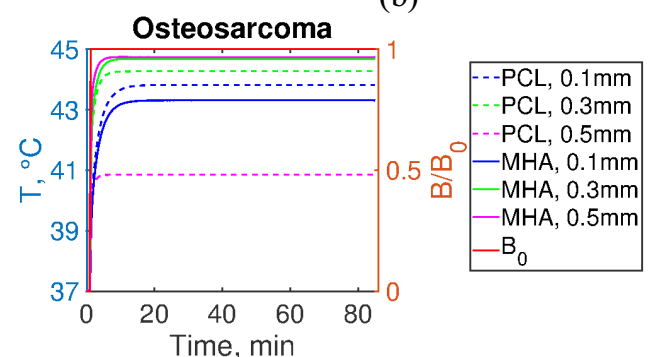

(c)

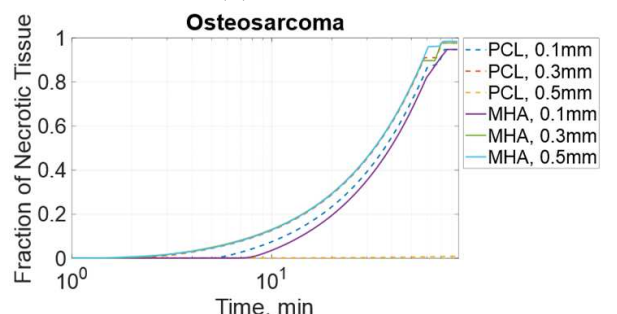

(d)

Fig. 5a. Average temperature increase in Fibrosarcoma region. 5b. Fraction of necrotic tissue for Fibrosarcoma (FS) in presence of an inflamed fracture. $\mathrm{B}_{0}=17 \mathrm{mT}$ for $\mathrm{FeHa} / \mathrm{PCL}$, whereas $20 \mathrm{mT}$ for MHA (at $293 \mathrm{kHz}$, as in [22]). Exposure time is $85 \mathrm{~min}$. The optimal applied field can be modeled as a descending ramp since FS is a low perfused tumor. Both magnetic biomaterials are able to kill $100 \%$ residual cancer cells, even for $r_{t}=0.5 \mathrm{~mm}$. 5c. Average temperature increase in Osteosarcoma region. MHA scaffolds are able to keep temperature above the therapeutic threshold. FeHa/PCL succeed for small tumor region $\left(\mathrm{r}_{\mathrm{t}}=0.1 \mathrm{~mm}\right)$ but is inadequate for tumors with radius higher than $0.3 \mathrm{~mm}$. 5d. Fraction of necrotic tissue for Osteosarcoma (OS) in presence of an inflamed fracture. Exposure time is $85 \mathrm{~min}$. 


\section{REFERENCES}

[1] C. D. Fletcher, K. K. Unni, \& F. Mertens, "Pathology and genetics of tumors of soft tissue and bone", vol. 4, Iarc, 2002, cap. 11, 12, pp. 224-231, 253-290

[2] F. Schajowicz, "Histological typing of bone tumours", Springer Science \& Business Media, 2012, cap. 1-7, pp.9-36

[3] T. D. Peabody \& S. Attar, "Orthopaedic Oncology", Springer International Publishing, 2016, cap. 1, 3, pp. 1-7, 203-206, 214-221.

[4] A. L. Folpe, "Fibrosarcoma: a review and update," Histopathology, vol. 64 , no. 1 , pp. $12-25,2014$

[5] J. S. Biermann et al., "NCCN Guidelines Insights: Bone Cancer, Version 2.2017.", Journal of the National Comprehensive Cancer Network, vol. 15. no. 2, pp. 155-167, 2017

[6] E. Skafida, et al., "Metastatic soft tissue sarcoma: current treatment landscape and future perspectives," Expert Review of Anticancer Therapy, vol. 17, no. 6, pp. 537-543, 2017.

[7] M. Parhizkar, S. Mahalingam, S. Homer-Vanniasinkam, M. Edirisinghe, "Latest developments in innovative manufacturing to combine nanotechnology with healthcare", Nanomedicine, vol. 13, no. 12018 , DOI: 10.2217/nnm-2017-0283, 2018

[8] M. Linch, A. B. Miah, K. Thway, I. R. Judson, C. Benson "Systemic treatment of soft-tissue sarcoma gold standard and novel therapies," Nature reviews Clinical oncology, vol. 11, no. 4, pp. 187-202, 2014.

[9] N. R. Datta, S. G. Ordóñez, U. S. Gaipl, M. M. Paulides, H. Crezee, J. Gellermann, D. Marder, E. Puric \& S. Bodis. "Local hyperthermia combined with radiotherapy and-/or chemotherapy: Recent advances and promises for the future," Cancer treatment reviews, vol. 41., no. 9, pp.742-753, 2015

[10] B. Hildebrandt, P. Wust, O. Ahlers, A. Dieing, G. Sreenivasa, T. Kerner, R. Felix, \& H. Riess. "The cellular and molecular basis of hyperthermia," Critical reviews in oncology/hematology, vol. 43, no. 1, pp. 33-56, 2002

[11] Q. Y. Fan, B. A. Ma, X. C. Qiu, Y. L. Li, J. Ye, Y. Zhou, "Preliminary report on treatment of bone tumors with microwave $\square$ induced hyperthermia," Bioelectromagnetics, vol. 17, no. 3, pp. 218-222, 1996

[12] D. Bahadur, G. Jyotsnendui, "Biomaterials and magnetism," Sadhana vol. 28, no. 3-4, pp. 639-656, 2003

[13] N. Bock, A. Riminucci, C. Dionigi, A. Russo, A. Tampieri, E. Landi, V. A. Goranov, M. Marcacci, V. Dediu, "A novel route in bone tissue engineering: magnetic biomimetic scaffolds," Acta Biomaterialia, vol. 6, no. 3, pp. 786-796, 2010.

[14] O. Bretcanu, E. Vernè, M. Cöisson, P. Tiberto, P. Allia, "Magnetic properties of the ferrimagnetic glass-ceramics for hyperthermia," Journal of magnetism and magnetic materials, vol. 305, pp. 529-533, 2006.

[15] M. Ikenaga, K. Ohura, T. Yamamuro, Y. Kotoura, M. Oka, T. Kokubo, "Localized hyperthermic treatment of experimental bone tumors with ferromagnetic ceramics," Journal of orthopaedic research, vol. 11, no. 6, pp. 849-855, 1993.

[16] A. Matsumine, K. Kusuzaki, T. Matsubara, K. Shintani, H. Satonaka, T. Wakabayashi, S. Miyazaki, K. Morita, K. Takegami, A. Uchida, "Novel hyperthermia for metastatic bone tumors with magnetic materials by generating an alternating electromagnetic field," Clinical \& experimental metastasis, vol. 24, no. 3, pp. 191-200, 2007

[17] G. Li, S. Feng, D. Zhou, "Magnetic bioactive glass ceramic in the system $\mathrm{CaO}-\mathrm{P} 2 \mathrm{O} 5-\mathrm{SiO} 2-\mathrm{MgO}-\mathrm{CaF} 2-\mathrm{MnO} 2-\mathrm{Fe} 2 \mathrm{O} 3$ for hyperthermia treatment of bone tumor," Journal of Materials Science: Materials in Medicine, vol. 22, no. 10, pp. 2197, 2011

[18] A. Matsumine, K. Takegami, K. Asanuma, T. Matsubara, T. Nakamura, A. Uchida, A. Sudo, "A novel hyperthermia treatment for bone metastases using magnetic materials," International journal of clinical oncology, vol. 16, no. 2, pp. 101-108, 2011

[19] M. Miola, R. Gerbaldo, F. Laviano, M. Bruno, E. Vernè, "Multifunctional ferrimagnetic glass-ceramic for the treatment of bone tumor and associated complications," Journal of Materials Science, vol. 52, no. 15, pp. 9192-9201, 2017.

[20] A. Ortolani, M. Bianchi, M. Mosca, S. Caravelli, M. Fuiano, M. Marcacci, A. Russo, "The prospective opportunities offered by magnetic scaffolds for bone tissue engineering: a review," Joints, vol. 4, no. 4, pp. 228, 2016.

[21] A. G. Kolhatkar, A. C. Jamison, D. Litvinov, R. C. Willson, T. R. Lee, "Tuning the magnetic properties of nanoparticles," International
Journal of Molecular Sciences, vol. 14, no. 8, pp. 15977-16009, 2013.

[22] M. Bañobre-López, Y. Pineiro-Redondo, M. Sandri, A.Tampieri, R De Santis, V. A. Dediu, J. Rivas, "Hyperthermia induced in magnetic scaffolds for bone tissue engineering," IEEE Transactions on Magnetics, vol. 50, no. 11, Nov. 2014, Art. no. 5400507.

[23] A. Tampieri, T. D’Alessandro, M. Sandri, S. Sprio, E. Landi, L. Bertinetti, S. Panseri, G. Pepponi, J. Goettlicher, M. Banorbre-Lopez, J. Rivas, "Intrinsic magnetism and hyperthermia in bioactive $\mathrm{Fe}-$ doped hydroxyapatite," Acta biomaterialia, vol. 8, no. 2, pp. 843$851,2012$.

[24] R. K. Singh, M. Srivastava, N. K. Prasad, S. Awasthi, A. Dhayalan, S. Kannan, "Iron doped $\beta$-Tricalcium phosphate: Synthesis, characterization, hyperthermia effect, biocompatibility and mechanical evaluation," Materials Science and Engineering: $C$, vol. 8, pp. 715-726, 2017.

[25] Y. Zhang, D. Zhai, M. Xu, Q Yao, J Chang, C. Wu, "3D-printed bioceramic scaffolds with a $\mathrm{Fe} 3 \mathrm{O} 4 /$ graphene oxide nanocomposite interface for hyperthermia therapy of bone tumor cells," Journal of Materials Chemistry B, vol. 4, no. 17,pp. 2874-2886, 2016

[26] A. Farzin, M. Fathi, R. Emadi, "Multifunctional magnetic nanostructured hardystonite scaffold for hyperthermia, drug delivery and tissue engineering applications," Materials Science and Engineering C, vol. 70, pp. 21-31, 2017

[27] S. Aliramaji, A. Zamanian, M. Mozafari, "Super-paramagnetic responsive silk fibroin/chitosan/magnetite scaffolds with tunable pore structures for bone tissue engineering applications," Materials Science and Engineering C, vol. 70, pp. 736-744, 2017

[28] Z. Karahaliloğlu, E. Yalçın, M. Demirbilek, E. B. Denkbaş, "Magnetic silk fibroin e-gel scaffolds for bone tissue engineering applications," Journal of Bioactive and Compatible Polymers, Art. no. 0883911517693635,2017

[29] S. K. Samal, V. Goranov, M. Dash, A. Russo, T. Shelyakova, P. Graziosi, L. Lungaro, A. Riminucci, M. Uhlarz, M. Banobre-Lopez, J. Rivas, T. Hermannsdorfer, J. Rajadas, S. De Smedt, K. Braeckmans, D. L. Kaplan, V. A. Dediu, "Multilayered magnetic gelatin membrane scaffolds," ACS applied materials \& interfaces, vol. 7, no. 41, pp. 23098-23109, 2015.

[30] R. E. Rosensweig, "Heating magnetic fluid with alternating magnetic field," Journal of magnetism and magnetic materials, vol. 252, pp. 370-374, 2002.

[31] R. Hergt, R. Hiergeist, M. Zeisberger, G. Glöckl, W. Weitschies, L. P. Ramirez, I. Hilger, W. A. Kaiser, "Enhancement of AC-losses of magnetic nanoparticles for heating applications," Journal of Magnetism and Magnetic Materials, vol. 280, no. 2, pp. 358-368, 2004

[32] D. B. Reeves, J. B. Weaver, "Approaches for modeling magnetic nanoparticle dynamics," Critical Reviews in Biomedical Engineering, vol. 42, no. 1, 85-93, 2014.

[33] S. B. Trisnanto, Y. Kitamoto, "Field-dependent Brownian relaxation dynamics of a superparamagnetic clustered-particle suspension," Physical Review E, vol. 90, no. 3, 032306.

[34] A. Fanti, M. B. Lodi, G. Mazzarella, "Enhancement of Cell Migration Rate Toward a Superparamagnetic Scaffold Using LF Magnetic Fields," IEEE Transactions on Magnetics, vol. 52, no. 10, Art. no. 5200508 Oct. 2016

[35] M. B. Lodi, A. Fanti, S. Casu, "Analysis of superparamagnetic scaffolds: For bone tissue engineering in static magnetic and dynamic fields," In Antennas \& Propagation Conference (LAPC), Nov. 2016 Loughborough, IEEE

[36] S. Laurent, D. Forge, M. Port, A. Roch, C. Robic, L. Vander Elst, R. N. Muller, "Magnetic iron oxide nanoparticles: synthesis, stabilization, vectorization, physicochemical characterizations, and biological applications," Chemical reviews, vol. 108, no. 6, pp. 20642110,2008

[37] Q. A. Pankhurst, J. Connolly, S. K. Jones, J. J. Dobson, "Applications of magnetic nanoparticles in biomedicine," Journal of physics D: Applied physics, vol. 36, no. 13, R167, R181, 2003.

[38] R. Hergt, W. Andra, C. G. d'Ambly, I. Hilger, W. A. Kaiser, U. Richter, H. Schmidt, "Physical limits of hyperthermia using magnetite fine particles," IEEE Transactions on Magnetics, vol. 34, no. 5 , pp. 3745-3754, 1998.

[39] A. Fanti, M. Spanu, M. B. Lodi, F. Desogus, G. Mazzarella, "Nonlinear Analysis of Soil Microwave Heating: Application to 
Agricultural Soils Disinfection," IEEE Journal on Multiscale and Multiphysics Computational Techniques, vol. 2, pp. 105-114, 2017.

[40] D. L. Leslie-Pelecky, R. D. Rieke, "Magnetic properties of nanostructured materials," Chemistry of materials, vol. 8, no. 8, pp. 1770-1783, 1996

[41] L. Dormann, F. D'Orazio, F. Lucari, E. Tronc, P. Prené, J. P. Jolivet, D. Fiorani, R. Cherkaoui, M. Nogues, "Thermal variation of the relaxation time of the magnetic moment of $\gamma$-Fe 2 O 3 nanoparticles with interparticle interactions of various strengths," Physical Review $B$, vol. 53, no. 21, pp. 14291, 1996

[42] H. Arkin, L. X. Xu, K. R. Holmes, "Recent developments in modeling heat transfer in blood perfused tissues," IEEE Transactions on Biomedical Engineering, vol. 41, no. 2, pp. 97-107, 1994

[43] A. R. Khaled, K. Vafai, "The role of porous media in modeling flow and heat transfer in biological tissues," International Journal of Heat and Mass Transfer, vol. 46, no. 26, pp. 4989-5003, 2003.

[44] C. W. Song, "Effect of local hyperthermia on blood flow and microenvironment: a review," Cancer Research, vol. 44, no. 10 suppl., pp. $4721 \mathrm{~s}-4730 \mathrm{~s}, 1984$.

[45] K. R. Jain, K. Ward-Hartley, "Tumor blood flow-characterization, modifications, and role in hyperthermia," IEEE transactions on sonics and ultrasonics, vol. 31, no. 5, pp. 504-525, 1984.

[46] E. Y. K. Ng, N. M. Sudharsan, "An improved three-dimensional direct numerical modelling and thermal analysis of a female breast with tumour," Proceedings of the Institution of Mechanical Engineers, Part H: Journal of Engineering in Medicine, vol. 215, no. 1, pp. 25-37, 2001

[47] A. Bhargava, A. Chanmugam, C. Herman, "Heat transfer model for deep tissue injury: a step towards an early thermographic diagnostic capability," Diagnostic pathology, vol. 9, no. 1, 717-723, 2014.

[48] S. A. Sapareto, W. C. Dewey "Thermal dose determination in cancer therapy," International Journal of Radiation Oncology*Biology* Physics, vol. 10, no. 6, pp. 787-800, 1984.

[49] M. Mital, H. V. Tafreshi, "A methodology for determining optimal thermal damage in magnetic nanoparticle hyperthermia cancer treatment," International journal for numerical methods in biomedical engineering, vol. 28, no. 2, pp. 205-213, 2012

[50] G. Augustin, S. Davila, K. Mihoci, T. Udiljak, D. S. Vedrina, A. Antabak, "Thermal osteonecrosis and bone drilling parameters revisited," Archives of orthopaedic and trauma surgery, vol. 128, no. 1, pp. 71-77, 2008J

[51] E. B. Dolan, T. J. Vaughan, G. L. Niebur, C. Casey, D. Tallon, L. M. McNamara, "How bone tissue and cells experience elevated temperatures during orthopaedic cutting: an experimental and computational investigation," Journal of biomechanical engineering, vol. 136 , no. 2, 021019

[52] J. Meng, B. Xiao, Y. Zhang, J. Liu, H. Xue, J. Lei, H. Kong, Y. Huang, Z. Jin, N. Gu, H. Xu, "Super-paramagnetic responsive nanofibrous scaffolds under static magnetic field enhance osteogenesis for bone repair in vivo," Scientific reports, 3, 2655, 2013

[53] A. Bailon-Plaza, M. C. Van Der Meulen, "A mathematical framework to study the effects of growth factor influences on fracture healing," Journal of Theoretical Biology, vol. 212, no. 2, pp. 191-209, 2001.

[54] T. Albrektsson, C. Johansson, "Osteoinduction, osteoconduction and osseointegration," European Spine Journal, vol. 10, S96-S101, 2001

[55] O. Kaygili, S. V. Dorozhkin, T. Ates, A. A. Al-Ghamdi, F. Yakuphanoglu, "Dielectric properties of Fe doped hydroxyapatite prepared by sol-gel method," Ceramics International, vol. 40, no. 7 , pp. $9395-9402,2014$

[56] C. C. Silva, M. P. F. Graça, M. A. Valente, A. S. B. Sombra, "AC and DC conductivity analysis of hydroxyapatite and titanium calcium phosphate formed by dry ball milling," Journal of non-crystalline solids, vol. 352, no.9, pp. 1490-1494, 2006

[57] R. Sabater i Serra, J. L. Escobar Ivirico, J. M. Meseguer Dueñas, A. A. Balado, J. L. Gómez Ribelles, M. Salmerón Sánchez, "Segmental dynamics in poly ( $\varepsilon \square$ caprolactone)/poly (L $\square$ lactide) copolymer networks," Journal of Polymer Science Part B: Polymer Physics, vol. 47, no. 2, pp. 183-193, 2009

[58] B. Kuttich, C. Lederle, B. Stühn, "Water dependence of the dielectric $\beta$-relaxation in poly ( $\varepsilon$-caprolactone)," The Journal of chemical physics, vol. 139, no. 24, 2013, Art. no. 244907
[59] S. Symeonidis, W. G. Whittow, C. Panagamuwa, "Characterisation of an antenna system implanted into a limb phantom for monitoring of bone fracture healing," In Antennas \& Propagation Conference (LAPC), Nov. 2016 Loughborough, IEEE.

[60] A. Swarup, S. S. Stuchly, A. Surowiec, "Dielectric properties of mouse MCA1 fibrosarcoma at different stages of development," Bioelectromagnetics, vol. 12, no. 1, pp. 1-8, 1991

[61] C. Rossmann, D. Haemmerich, "Review of temperature dependence of thermal properties, dielectric properties, and perfusion of biological tissues at hyperthermic and ablation temperatures," Critical Reviews ${ }^{\mathrm{TM}}$ in Biomedical Engineering, vol. 42, n. 6, 2014.

[62] F. A. Duck, Physical properties of tissues: a comprehensive reference book, Academic press, 2013.

[63] P.A. Hasgall, F. Di Gennaro, C. Baumgartner, E. Neufeld, M.C. Gosselin, D. Payne, A. Klingenböck, N. Kuster, IT'IS Database for thermal and electromagnetic parameters of biological tissues, Version 3.0, 2015. www.itis.ethz.ch/database.

[64] B. P. Ayati, C. M. Edwards, G. F. Webb, J. P. Wikswo, "A mathematical model of bone remodeling dynamics for normal bone cell populations and myeloma bone disease," Biology direct, vol. 5, no. 28 , pp. $1-172010$

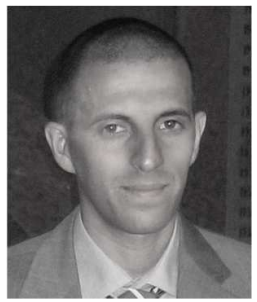

Alessandro Fanti received the Laurea degree in electronic engineering and Ph.D. degree in Electronic Engineering and computer science from the University of Cagliari, Cagliari, Italy, in 2006 and 2012, respectively. He worked as post-doctoral fellow in the Electromagnetic Group at the University of Cagliari from 2013 to 2016, where he is currently an Assistant Professor. His research activity involves the use of numerical techniques for modes computation of guiding structures, optimization techniques, analysis and design of waveguide slot arrays, analysis and design of patch antennas, radio propagation in urban environment, modelling of bioelectromagnetic phenomena, microwave exposure systems for biotechnology and bio-agriculture

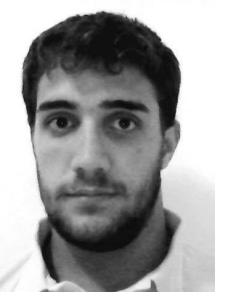

M. B. Lodi was born in Cagliari January 15, 1994. He achieved the Bachelor degree in Biomedical Engineering on March 2016 at University of Cagliari. His current research interests include the modelling of bio-electromagnetic phenomena, the study magnetic biomaterials for tissue engineering applications and the use of microwave in biotechnology and environmental applications.

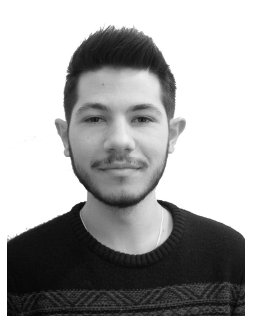

Giuliano Vacca was born in Iglesias, Italy, in 1994. He received the bachelor's degree in biomedical engineering from the University of Cagliari, Cagliari, Italy, in 2018. His research interests include multiphysics modelling of deep magnetic induction hyperthermia using magnetic material and the interaction between electromagnetic energy with biosystems. 


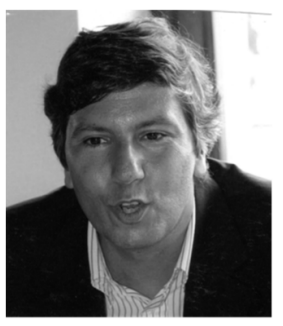

Giuseppe Mazzarella (S '82, M' 90 , SM'99), graduated Summa with Laude in Electronic Engineering from the Università Federico II of Naples in 1984 and subsequently obtained the Ph.D. in Electronic Engineering and Computer Science in 1989. In 1990 he became Assistant Professor at the Dipartimento di Ingegneria Elettronica at the Università Federico II of Naples. Since 1992 he is with the Dipartimento di Ingegneria Elettrica ed Elettronica of the Università di Cagliari, first as associate professor and then, since 2000, as full professor, teaching courses in Electromagnetics, Microwave, Antennas and Remote Sensing. His research activity has focused mainly on: efficient design of large arrays of slots, power synthesis of array factor, with emphasis on inclusion of constraints, microwave holography techniques for the diagnosis of large reflector antennas, use of evolutionary programming for the solution of inverse problems, in particular problems of synthesis of antennas and periodic structures. He is author (or coauthor) of over 70 papers in international journals, and is a reviewer for many EM journals. 